\title{
Gamified Digital Services: How Gameful Experiences Drive Continued Service Usage
}

\author{
Tobias Wolf \\ University of Goettingen \\ tobias.wolf@wiwi. \\ uni-goettingen.de
}

\author{
Welf H. Weiger \\ University of Goettingen \\ welf.weiger@wiwi. \\ uni-goettingen.de
}

\author{
Maik Hammerschmidt \\ University of Goettingen \\ maik.hammerschmidt@wiwi. \\ uni-goettingen.de
}

\begin{abstract}
Recently, many digital service providers started to gamify their services to promote continued service usage. Although gamification has drawn attention in both practice and research, it remains unclear how users experience gamified services and how these gameful experiences may increase service usage. This research adopts a user-centered perspective to reveal the underlying gameful experience dimensions during gamified service usage and how they drive continued service usage. Findings from Study 1 - a survey with 148 app-users - reveal four essential gameful experience dimensions (skill development, social comparison, social connectedness, and expressive freedom) and how they relate to game mechanics. Study 2, which is based on a survey among 821 app-users, shows that gameful experiences trigger continued service usage through two different types of motivation, namely autonomous and controlled motivation.
\end{abstract}

\section{Introduction}

Digital service providers - suppliers of mobile or web applications - increasingly count on business models where revenues are predominantly generated by advertising, in-app purchases, or paid-premium upgrades instead of service purchases [23, 31]. Suppliers of mobile apps, for instance, vitally depend on establishing continued app usage in order to make their digital services profitable. However, $63 \%$ of users do not reuse a newly installed mobile app more than ten times [30].

To encourage users to continue service usage, firms have started to gamify digital services across many different contexts such as fitness, nutrition, or education [18]. The idea of gamification is to leverage the

\footnotetext{
${ }^{1}$ We define desired activities as the activities users want to engage in for various reasons. We note that digital services are designed to
}

motivational power of games to support users to perform desired activities ${ }^{1}$ (e.g., exercising, healthy eating or studying) and attain personal goals related to these activities [28]. Thus, gamification aims at increasing service usage by employing game mechanics, such as points or badges, to establish gameful experiences, such as achievement or competition $[11,21,41]$. Therefore, gamified services non-game services that are augmented with game mechanics - aim to foster continued service usage by motivating users to perform desired activities $[11,15$, $18,21]$.

For instance, by gamifying their running app, Nike attained an active user base containing 28 million athletes in 2014 [4]. However, removing some of the game mechanics (e.g., badges) in 2016 led to severe dissatisfaction and to discontinued app usage among customers [48]. As demonstrated by this managerial misjudgment, firms are unaware of how users experience gamified services and how this eventually leads to continued digital service usage. Specifically, service providers need to know the nature of experiences that are associated with distinct game mechanics and to understand how gameful experiences nurture user motivations and effectively drive continued service usage.

Although prior research has already attempted to analyze the relationship between game mechanics and usage intention (e.g., $[15,32]$ ), or how specific game mechanics influence general user activity (e.g., [14]), there is still a lack of understanding of, first, how gameful experiences relate to game mechanics, and second, how they lead to continued service usage. These gaps are a result of prior research primarily taking on a design-oriented perspective (i.e., game mechanics) when examining the effectiveness of gamified services. To fill these gaps and to provide practical insights for managers who seek to enhance digital service usage, we

support users to perform these predefined activities and users choose a service for this exact purpose. 
adopt a user-centered perspective by focusing on gameful experiences [21].

In this research, we aim at understanding how different dimensions of gameful experiences influence continued service usage. To achieve this goal, we conduct two studies. In Study 1, we employ a factor analytical approach to empirically identify dimensions of gameful experience. Then, we conduct a cluster analysis to link gameful experiences to specific game mechanics and thereby reveal how service designers can best foster desired experiences. In Study 2, we draw on self-determination theory (SDT) to conceptualize a framework that links gameful experience dimensions to continued service usage through two motivational paths, namely autonomous and controlled motivation. We test this framework using seemingly unrelated regressions (SUR).

Our research contributes to the service marketing literature in general and to the emerging literature on gamification specifically. First, we shift the predominantly design-oriented understanding of gamification towards a more user-centric view by revealing how game mechanics relate to various gameful experiences. In doing so, we can identify generic dimensions of gameful experiences and group distinct manageable game mechanics based on their associations with gameful experiences. Second, we contribute to service marketing research by establishing a conceptual and empirical understanding of how gamified services may impact continued service usage through motivation. Specifically, the results of Study 2 demonstrate the need to consider two types of motivation - autonomous and controlled motivation - to fully understand how gameful experiences motivate users to perform desired activities, which in turn manifests in continued service usage. Importantly, by considering controlled motivation as a so far neglected counterpart to autonomous motivation, we move beyond prior research (e.g., [17, 27, 40, 42]) to additionally allow for perceived pressure as a driver of service usage.

\section{Study 1: Capturing gameful experience dimensions}

\subsection{Gamification of digital services}

2.1.1. Game mechanics. The main purpose of gamified services is to support users in performing desired activities that are, for instance, sport, nutrition, or education related. To provide users with feedback on the performance of their activities, service providers rely on game mechanics, which refer to components that establish a structured set of goals for performing the desired activities and to issue intangible rewards upon goal accomplishment $[18,35]$. Importantly, mechanics represent objective components of gamified apps typically specified by designers. Common game mechanics are points, badges, or quests.

Notably, prior research has identified a conglomerate of different game mechanics (e.g., [3, 16, $24,25,43,45])$. Accordingly, in the first step, we draw on existing literature overviews (e.g., [16, 25]), and quantitative research (e.g., [13, 40, 45, 47]) as well as qualitative research [24] to identify common game mechanics in gamified services, which resulted in 24 at least partially different game mechanics. In the second step, we continued by randomly selecting 50 real-life gamified apps (e.g., MyFitnessPal, Foursquare) with not less than 500,000 downloads. More specifically, we trained two research assistants, who were blind to our research goal, to conduct a search in the Google Play Store and Apple App Store to identify gamified apps based on the definitions of gamified services and game

Table 1: Common game mechanics in literature and practice of gamified digital services

\begin{tabular}{|c|c|c|}
\hline Game Mechanics & Description & Literature \\
\hline Avatars & Images of users, which visually represent them in the service community & e.g., [25] \\
\hline Badges & $\begin{array}{l}\text { Signs of attainment that are awarded to users after successful completing of a quest, } \\
\text { task or attaining a milestone }\end{array}$ & e.g., [16] \\
\hline Chats & Enables users to message each other in real-time & e.g., [42] \\
\hline Friending & Enables users to add other users to their social network (e.g., friend list) & e.g., [47] \\
\hline Leaderboards & Rankings of users based on their relative performance in service-focal activities & e.g., [16] \\
\hline Performance Graphs & Visualizations of user-specific statistics based on their activities (e.g., diagrams) & e.g., [40] \\
\hline Points & Units that measure user performance through completion of specific tasks & e.g., [25] \\
\hline Progress Notifications & Indication of the extent to which quests, tasks or milestones have been completed & e.g., [25] \\
\hline Quests & Predefined objectives that users should reach by performing activities & e.g., [45] \\
\hline Social Feedback & Enables users to react to other users' activities (e.g., thumbs up) & e.g., [25] \\
\hline Teams & Groups of users that are formed to achieve a common goal & e.g., [40] \\
\hline User Levels & Representation of the current skill levels of users & e.g., [16] \\
\hline User Profiles & Personalized virtual identities of users in the service community & e.g., [3] \\
\hline
\end{tabular}


Table 2: Common gameful experiences in the context of gamified digital services

\begin{tabular}{|c|c|c|}
\hline Gameful Experiences & Description & Literature \\
\hline Achievement & Experience of reaching own goals & e.g., [25] \\
\hline Challenge & Experience of being claimed by a task & e.g., [3] \\
\hline Choice Perception & Experience of having the possibility to do things the own way & e.g., [6] \\
\hline Competition & Experience of rivalry with other users & e.g., [25] \\
\hline Cooperation & Experience of working with other users & e.g., [3] \\
\hline Progress & Experience of own development & e.g., [25] \\
\hline Self-expression & Experience of communicating one's own identity in the service community & e.g., [43] \\
\hline Social Interaction & Experience of communicating with one another & e.g., [25] \\
\hline Status & Experience of presenting one's own social rank within the service community & e.g., [43] \\
\hline
\end{tabular}

mechanics. In the third step, we compared the mechanics identified in step one to those contained in the 50 apps selected in step two. Finally, we extracted 13 state-of-the-art game mechanics that occurred in at least three of the 50 gamified apps (see Table 1 for overview and descriptions).

2.1.2. Gameful experiences. Gameful experiences refer to user perceptions of the benefit creation associated with game mechanics during digital service usage (e.g., achievement, challenge, self-expression) [11, 21]. Importantly, different gameful experiences may be related to the same game mechanic and, vice versa, one gameful experience may be associated with multiple game mechanics [44]. Importantly, managers need to know how specific game mechanics manifest in gameful experiences to assess their effectiveness in motivating service usage.

Prior literature discusses a wide variety of game experiences (e.g., [3, 6, 13, 25, 43]). To select distinctive gameful experiences associated with gamified services, we first identified 18 at least partially different gameful experiences mentioned in prior literature. To validate our selection of gameful experiences, we relied on a focus group. Specifically, we invited ten experienced users $^{2}$ of gamified digital services. The objective of the focus group discussion was to identify the most common experiences in the context of gamified services. Guided by our preselection of gameful experiences, the users discussed their experiences during service usage. First, the focus group debated which of the 18 gameful experiences usually occur during gamified service usage. In the next step, they discussed whether these gameful experiences merely occur when using specific apps or when using multiple gamified apps. As a result of the focus group discussion, we identified nine gameful experiences that are common

\footnotetext{
${ }^{2}$ It was required that each participant had used at least one gamified digital service (e.g., Runtastic, Duolingo) two times a week for at least six months
}

across gamified apps. Table 2 provides an overview and description of the selected gameful experiences.

\subsection{Methodology}

In this study, we aim to reveal the underlying dimensions of gameful experiences on the basis of the specific game mechanics they relate to.

First, for each gameful experience, we adapted three items from prior literature. Then we conducted a prestudy to select nine single items to represent each experience based on the highest item-rest correlation $(N=69$; see Table 2). Second, in the main study, we conducted a survey to indicate whether these experiences actually relate to each of the 13 game mechanics shown in Table 1. At the beginning of the study, participants could select one to five game mechanics with which they are familiar in the context of mobile apps (the app context was not further restricted). We excluded participants who had never perceived any game mechanic. For each of the mechanics, the participants answered the nine single items identified in the pre-study to capture their gameful experiences (e.g., "Points help me to reach a goal"; anchored by $1=$ strongly disagree and $7=$ strongly agree). Each participant rated between one to five game mechanics depending on their selection at the beginning of the survey. At the end of the survey, the participants stated their age, gender, and education level. A sample of 148 respondents completed the survey, of which $57 \%$ were female, $60 \%$ were academics, and the average age was 26.96 years $(S D=7.52)$. As each respondent could evaluate up to five mechanics, we ended up with a total of 471 rated game mechanics in terms of gameful experiences evoked. 


\subsection{Results and Discussion}

We conducted an exploratory factor analysis to identify gameful experience dimensions and extracted four factors (variance explained $=77 \%$; see Table 3 ). Each gameful experience loaded higher on one of the factors than on the other ones, in support of the discriminant validity of the factors extracted.

Factor 1 is strongly related to achievement, challenge, and progress. Taken together, this factor summarizes experiences that relate to the advancement of participants' own capabilities and we therefore refer to this dimension as skill development. Factor 2 is strongly related to competition and status. As these experiences are characterized by comparing oneself to others, we coin this dimension as social comparison. Factor 3 is strongly associated with cooperation and social interaction. This represents the experience of being connected to others, and thus we refer to this dimension as social connectedness. Finally, Factor 4 is strongly associated with choice perception and selfexpression. Consequently, this dimension is referred to as expressive freedom.

In the next step, we conducted a cluster analysis to capture the degree to which distinct game mechanics relate to the different gameful experience dimensions extracted from the factor analysis. As mentioned above, it is important for service managers and app designers to understand how game mechanics relate to gameful experiences that may thereby trigger service usage. We used the regression factor scores resulting from the factor constellations displayed in Table 3 to conduct a hierarchical cluster analysis. Specifically, to reveal potential relations between mechanics and experience dimensions, we built clusters based on the average factor scores across all ratings of each game mechanic shown in Table 1 . The cluster analysis indicated a fourcluster solution where each cluster highly relates to a different gameful experience dimension (all other relations $M_{F S}<0.15$ ). Cluster 1 is composed of points, levels, and leaderboards and relates to social comparison $\left(M_{F S}=0.81 ; S D=0.48\right)$. Badges, quests, performance graphs, and progress notifications build Cluster 2, which is associated with skill development $\left(M_{F S}=0.67 ; S D=0.28\right)$. Cluster 3 summarizes avatars and user profiles and is related to expressive freedom $\left(M_{F S}=1.05 ; S D=0.18\right)$. Cluster 4 is composed of friending, teams, chats, and social feedback functions that are associated with social connectedness $\left(M_{F S}=\right.$ $0.96 ; S D=0.55)$. Consequently, specific game mechanics relate especially to one gameful experience dimension. These results yield meaningful implications by relating objective and managerially controllable game mechanics to gameful experiences. However, as we adopted a user-centered approach, we used the identified gameful experience dimensions to conceptualize our framework as drivers of continued digital service usage.

\section{Study 2: Examining the impact of gameful experiences on continued service usage}

\subsection{Theoretical underpinning: Self- determination theory}

In the context of digital service usage, SDT helps explain motivations of user behavior [37, 41]. Specifically, SDT assumes that although humans have innate tendencies to psychological growth and autonomous behavior, they may also act upon external motivational forces [39]. Thus, SDT suggests that motivation can be understood as a two-dimensional construct that relates low versus high selfdetermination.

Table 3: Results of factor analysis of gameful experiences

\begin{tabular}{lcccc}
\hline Gameful Experiences & Factor $\mathbf{1}$ & Factor $\mathbf{2}$ & Factor $\mathbf{3}$ & Factor $\mathbf{4}$ \\
\hline Achievement &. $\mathbf{8 4 1}$ & .080 & .097 & -.015 \\
Challenge & .830 & .182 & .120 & -.085 \\
Choice Perception & .420 & -.086 & .152 & .700 \\
Competition & .242 & .850 & -.039 & -.093 \\
Cooperation & .318 & .012 & .883 & .035 \\
Progress & .727 & .224 & -.083 & .146 \\
Self-expression & -.181 & .114 & .162 & .847 \\
Social interaction & -.196 & -.118 & .798 & .375 \\
Status & .119 & .885 & -.039 & .121 \\
\hline Eigenvalue & 2.346 & 1.631 & 1.499 & 1.400 \\
Variance explained & $26.35 \%$ & $18.12 \%$ & $16.65 \%$ & $15.55 \%$ \\
\hline Notes: Principal component analysis using varimax-rotation. Bold values indicate the factor on which each item predominantly loads \\
( $N=471$ game mechanics ratings with regard to users' experiences).
\end{tabular}


While behavior is perceived as highly selfdetermined when the performed activity results from one's own will, low self-determined behavior is associated with the feeling that the activity is externally promoted [39]. It is important to note that external stimuli like gamified apps provided by service firms do not necessarily lead to perceptions of external control [39]. Specifically, SDT suggests that external stimulation of behavior may be internalized into one's own sense of self and based on the degree of internalization results in the experience of autonomous or controlled motivation $[1,7,39]$.

When individuals perceive that their activities are important and valuable for themselves, they experience autonomous motivation, a drive to act based on enjoyment, interest, or attached value [12, 19, 39]. The sense of high self-determined behavior while performing an activity is linked to the satisfaction of three basic psychological needs: competence, relatedness, and autonomy [10]. More specifically, the need for competence refers to the urge to feel effective in one's ongoing actions; the need for relatedness is defined as the desire to feel connected to others; and the need for autonomy relates to perceiving oneself as the origin of behavior and expressing one's own self $[9,39]$. Thus, autonomous motivation may be fostered by providing users with positive feedback about their individual goal attainment. If an activity is based on perceived pressure, individuals experience controlled motivation, a drive to act, for instance, based on approval, feelings of shame, or avoiding guilt $[12,39]$. Consequently, individuals may use a digital service because other users may admire them for their performance, thus promoting feelings of worth. Likewise, service users might feel guilt or shame when stopping service usage because it makes them feel that they are failing their goals or that other service users could notice that they have become inactive. Importantly, both motivations may release the necessary psychological resources to develop the energy and willpower to repeatedly engage in an activity [38].

Previous gamification research that relied on SDT framework mainly focused on autonomous motivation and need satisfaction (e.g., [17, 27, 40, 42]). However, this represents a myopic perspective as external stimuli such as gamified digital services may also trigger controlled motivation. Accordingly, our framework considers both motivations to accommodate all theoretically relevant motivational paths to continued service usage.

\subsection{Conceptual model}

Ideally, gamified services motivate users to perform the desired activities and reach activity-related goals $[15,18,21]$, thereby fostering continued service usage. From a SDT perspective, a gamified service may act as an external stimulus that promotes an activity, which may or may not be internalized. Thus, gameful experiences may lead to autonomous motivation if they foster need satisfaction [28] or promote controlled motivation if they trigger perceived pressure [22]. Importantly, both motivations may exist in parallel and may operate simultaneously but independently of one another during gamified service usage [39]. Accordingly, while expecting that the previously identified gameful experience dimensions can be effective in fostering service usage, we argue that they function through different motivational paths. Figure 1 displays our proposed conceptual model that centers on users' autonomous and controlled motivation (see Table 4 for variable definitions).

In the following, we formulate our expectations on the relationships between gameful experiences and continued service usage through user motivation.

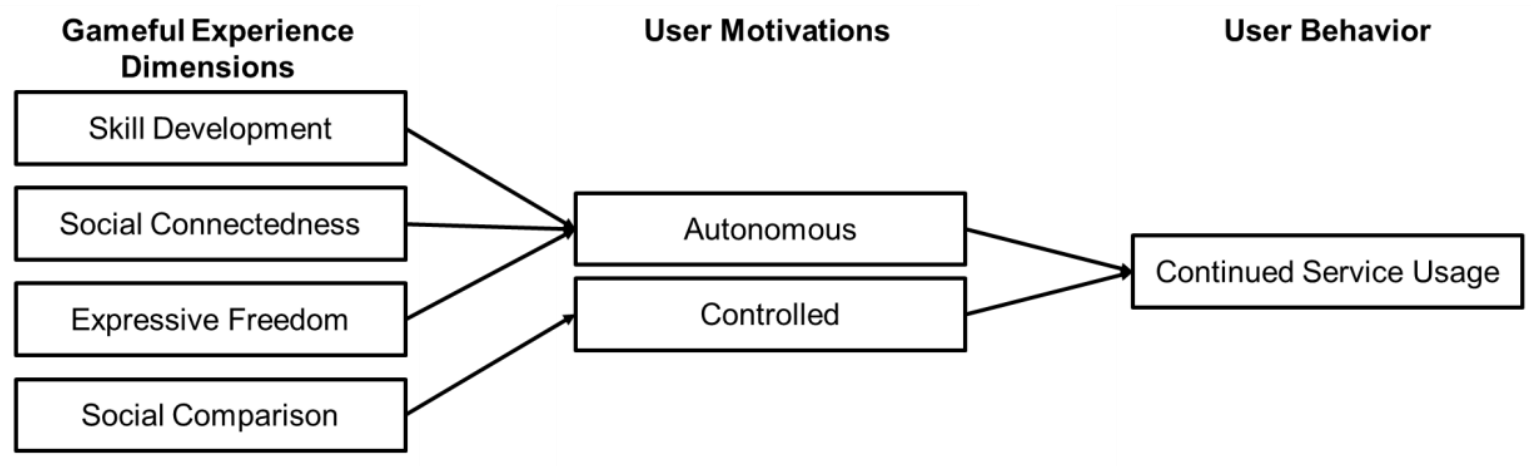

Figure 1: Conceptual model 
Table 4: Conceptual model variables

\begin{tabular}{ll}
\hline Variable & Definition \\
\hline $\begin{array}{c}\text { Gameful Experience Dimensions } \\
\text { Skill Development }\end{array}$ & $\begin{array}{l}\text { Experience of reaching own goals, being claimed by a task and advancing own } \\
\text { capabilities }\end{array}$ \\
Social Connectedness & $\begin{array}{l}\text { Experience of interacting with one another and working together on tasks within the } \\
\text { service community }\end{array}$ \\
Expressive Freedom & $\begin{array}{l}\text { Experience of the possibility to act on their own free will or to realize their individual } \\
\text { personalities }\end{array}$ \\
Social Comparison & Experience of rivaling with other users when performing an activity supported by a digital \\
& service
\end{tabular}

User Motivations

Autonomous Motivation Performing an activity because the gamified service promotes the satisfaction of autonomy, competence, and relatedness

Performing an activity because the gamified service triggers approval concerns, guilt or shame if the desired activity would not be performed

Continued Service Usage

The recurrent use of a digital service

We expect skill development, social connectedness, and expressive freedom to increase continued service usage through autonomous motivation. We propose that skill development, social connectedness, and expressive freedom satisfy basic psychological needs. Especially, we assume that the experience of skill development satisfies the need for competence because users feel effective in their behavior when they achieve personal goals, make progress, or master challenging tasks. Further, social connectedness stems from cooperation and interaction with other users and thereby satisfies the need for relatedness. Finally, expressive freedom satisfies the need for autonomy because users act in their own interest while performing the desired activity with the support of the digital service. SDT argues that facilitating the satisfaction of the need for competence, relatedness, or autonomy through a digital service triggers autonomous motivation, which leads to increased behavioral outcomes. Thus, autonomous motivation is likely to drive repetition of the desired activities with the support of the digital service, which results in continued service usage.

We expect social comparison to increase continued service usage through controlled motivation. Social comparison stems from directly competing with other users in the service community. Consequently, users may perform activities due to perceived pressures. For instance, users might engage in fitness activities because they don't want to feel ashamed for quitting or want to be admired for their performance, even if they don't enjoy the activity per se. Thus, by transmitting feelings of pressure, social comparison triggers controlled motivation, which in turn drives continued service usage.

\subsection{Methodology}

3.3.1. Research Design. To test our conceptual model, we conducted a large-scale survey to collect experience perceptions, motivations, and usage of actual users of real-life gamified apps.

First, in preparation for the survey, we selected popular gamified apps across different categories to establish a realistic research setting. Further, to achieve a representative sample, we made sure that the chosen apps had varying numbers of game mechanics. We questioned 443 students to identify the most often-used apps of the 50 gamified apps selected in Study 1. For every category, we included only apps that were mentioned by at least $10 \%$ of the participants. This procedure led to a selection of 14 apps in five categories, which we used for our main survey (see Table 5).

Table 5: Gamified apps selected for study 2

\begin{tabular}{llc}
\hline Category & App & $\begin{array}{c}\text { Number of } \\
\text { game mechanics }\end{array}$ \\
\hline Community & Chefkoch & 4 \\
& Tripadvisor & 8 \\
Education & Babbel & 9 \\
Fitness & Duolingo & 10 \\
& Freeletics & 11 \\
& Nike+ & 11 \\
Nutrition & Runtastic & 11 \\
& Liefesum & 4 \\
& FatSecret & 3 \\
& MyFitnessPal & 9 \\
Organization & Yazio & 3 \\
& Evernote & 3 \\
& Flatastic & 8 \\
& Wunderlist & 6 \\
\hline Note: The number of implemented game mechanics is based \\
on the list of game mechanics in Table 1.
\end{tabular}

Page 1192 
For the main survey, we recruited participants through several posts in different groups on Facebook or online forums. As an incentive for survey participation, four $25 €$ gift cards were raffled among the respondents. At the beginning of the study, participants could choose one of the 14 apps based on their personal usage and experience. If the participants had never used any of the 14 apps, they were excluded from the survey. After choosing an app and specifying which app version they used, the respondents answered questions about their actual app usage during the last four weeks. Participants were encouraged to base their self-reports on the app's usage history or performance overview. Then the participations answered questions about their gameful experiences, motivation, and several control variables. All apps mentioned in Table 5 were chosen by at least 15 participants. The survey was completed by 821 participants. The respondents were $64 \%$ female and averaged 27.46 years old $(S D=7.95)$. On average, a participant used the focal app for 19.30 months $(S D=$ $16.05 ; \min =1$ week, $\max =72$ months).

3.3.2. Measures. We captured continued app usage through self-reporting of app usages during the last four weeks. We captured gameful experiences by taking the mean across all corresponding items for each of the four factors developed in Study 1 (e.g., "[App] helps me to develop myself"; 1 = strongly disagree and 7 = strongly agree). The Cronbach's alphas confirm construct reliability for all four gameful experience dimensions $(\alpha>.73)$ except for expressive freedom $(\alpha=.50)$. We measured autonomous (controlled) motivation using six (three) items adapted from [36] (e.g., autonomous motivation: "I am doing sports with [App], because I enjoy it"; controlled motivation: "I am doing sports with [App], because I would have felt bad about myself if I didn't"; $1=$ "strongly disagree" and $7=$ "strongly agree"; $\alpha>.87)$. We captured goal commitment as an control variable using three items adapted from [20] (e.g., "I think this goal is a good goal to shoot for"; $1=$ "strongly disagree" and $7=$ "strongly agree"; $\alpha=.89$ ). The remaining control variables were measured using single items: brand attitude [2], ease of use [29], aesthetics [26], and technology experience [32]. We also controlled for app usage length, operating system, app version, age, and gender using single items. Items are available upon request.

\subsection{Results \& Discussion}

We deemed SUR as appropriate for testing our conceptual model because it meets three important requirements. First, SUR accounts for correlated error terms across different equations [46]. Second, SUR allows us to estimate the direct and indirect effects in our model simultaneously, which allows for an assessment of mediation effects [33]. Third, the dependent variables in our model (continuous data on autonomous and controlled motivation) and the behavioral outcome model (skewed count data of service usage) follow different distributions. SUR allows to account for different density functions across equations [5].

We provide the results of the SUR models in Table 6 . The results show positive and significant effects of skill development $(b=.184, p \leq .001)$, social connectedness $(b=.033, p \leq .05)$, and expressive freedom $(b=.094, p \leq .001)$ on autonomous motivation. Social comparison has no significant influence on autonomous motivation $(b=.003, p>.10)$. In contrast, only social comparison shows a positive effect on controlled motivation $(b=.047, p \leq .05$; all others $b<|.02|$, $p>.10)$. Autonomous $(b=.178, p<.001)$ and controlled motivation $(b=.087, p \leq .05)$ have positive and significant effects on continued service usage.

To test for mediation, we estimated direct and indirect effects simultaneously using bootstrapped SUR (5,000 draws) that build on an empirical sampling distribution of the indirect effects $[34,49]$. We estimate the indirect effects using the products of coefficient approach. Results show that autonomous motivation mediates the positive effect of skill development $(b=.033$, lower-level confidence interval [LLCI] $=$ .015 , upper-level confidence interval $[\mathrm{ULCI}]=.052)$, social connectedness $(b=.006$, LLCI $=.001, \mathrm{ULCI}=$ $.014)$, and expressive freedom $(b=.017$, LLCI $=.007$, ULCI $=.030)$ on continued service usage. Controlled motivation mediates the positive effects of social comparison on service usage $(b=.004$, LLCI $=.000$, $\mathrm{ULCI}=.012$ ). Every effect of gameful experiences on service usage was fully mediated except the effect of social comparison.

Our results provide empirical evidence of service usage enhancing effects of gameful experiences and reveal the underlying motivational paths. Importantly, as we expected, not all gameful experiences enhance service usage through autonomous motivation. To fully understand the motivational effect of gamified digital services, it is necessary to consider controlled motivation, as we show that it serves as a mediator for the effect of social comparison on continued service usage.

\section{Conclusion \& Implications}

Digital service providers are concerned with how game mechanics manifest in gameful experiences and how they drive user retention $[18,30]$. However, it is not well understood which dimensions of gameful 
Table 6: Results of direct effects in study 2

\begin{tabular}{|c|c|c|c|c|c|c|}
\hline \multirow[b]{2}{*}{ Independent Variable } & \multicolumn{2}{|c|}{ Autonomous Motivation } & \multicolumn{2}{|c|}{ Controlled Motivation } & \multicolumn{2}{|c|}{ Service Usage } \\
\hline & Coefficient & SE & Coefficient & SE & Coefficient & SE \\
\hline Constant & $-3.585^{\star \star \star}$ & .180 & $.194^{\text {n.s. }}$ & .245 & $2.040^{\star \star \star}$ & .263 \\
\hline \multicolumn{7}{|l|}{ Gameful Experience Dimensions } \\
\hline Skill Development & $.184^{\star \star \star}$ & .021 & $-.011^{\text {n.s. }}$ & .029 & & \\
\hline Social Connectedness & $.033^{\star}$ & .017 & $-.002^{\text {n.s. }}$ & .023 & & \\
\hline Expressive Freedom & $.094^{* * *}$ & .021 & $.019^{\text {n.s. }}$ & .028 & & \\
\hline Social Comparison & $.003^{\text {n.s. }}$ & .017 & $.047^{\star}$ & .024 & & \\
\hline \multicolumn{7}{|l|}{ User Motivations } \\
\hline Autonomous Motivation & & & & & $.178^{\star \star *}$ & .042 \\
\hline Controlled Motivation & & & & & $.087^{*}$ & .034 \\
\hline \multicolumn{7}{|l|}{ Controls } \\
\hline Category Education & $.771^{\star \star \star}$ & .087 & $.003^{\text {n.s. }}$ & .119 & -.104 & .111 \\
\hline Category Fitness & $1.177^{\star * \star}$ & .075 & $.407^{\star * *}$ & .102 & $-.370^{\star \star *}$ & .103 \\
\hline Category Nutrition & $.731^{\star * *}$ & .079 & $1.130^{* * *}$ & .107 & $.803^{\star * *}$ & .107 \\
\hline Category Organization & $-.109^{\text {n.s. }}$ & .092 & $.520^{\star * *}$ & .119 & $.539^{\star \star \star}$ & .117 \\
\hline Goal Commitment & $.049^{* *}$ & .018 & $.089^{\star * *}$ & .025 & $.057^{*}$ & .023 \\
\hline App Usage Length & $-.001^{\text {n.s. }}$ & .001 & $-.001^{\text {n.s. }}$ & .001 & $.001^{\text {n.s. }}$ & .001 \\
\hline Brand Attitude & $.086^{\star * *}$ & .025 & $.058^{\text {n.s. }}$ & .034 & $.006^{\text {n.s. }}$ & .030 \\
\hline Ease of Use & $.044^{\text {n.s. }}$ & .028 & $-.156^{\star \star *}$ & .038 & $-.039^{\text {n.s. }}$ & .036 \\
\hline Aesthetics & $.088^{* * *}$ & .022 & $.009^{\text {n.s. }}$ & .030 & $.060^{*}$ & .027 \\
\hline Technology Experience & $.026^{\text {n.s. }}$ & .015 & $-.005^{\text {n.s. }}$ & .020 & $.050^{* *}$ & .019 \\
\hline $\begin{array}{l}\text { Operating System } \\
(0=\mathrm{iOS} \text { or Windows; } 1=\text { Android })\end{array}$ & $-.010^{\text {n.s. }}$ & .045 & $.071^{\text {n.s. }}$ & .061 & $.146^{\star}$ & .059 \\
\hline $\begin{array}{l}\text { App Version } \\
(0=\text { Free Version; } \\
1 \text { = Premium Version })\end{array}$ & $-.156^{\star}$ & .065 & $.267^{\star \star}$ & .088 & $.441^{\star * \star}$ & .084 \\
\hline Age & $.005^{\text {n.s. }}$ & .003 & $-.022^{\star \star *}$ & .004 & $.012^{\star *}$ & .004 \\
\hline Gender & $-.045^{\text {n.s. }}$ & .049 & $-.064^{\text {n.s. }}$ & .066 & $-.159^{\star}$ & .063 \\
\hline
\end{tabular}

\begin{tabular}{|c|c|c|c|}
\hline Ln alpha ${ }^{a}$ & & & $-.512^{\star \star \star}$ \\
\hline Adj. $R^{2}$ & .605 & .266 & \multirow{2}{*}{$\begin{array}{c}.06 \\
2.810\end{array}$} \\
\hline Max. VIFc & 2.520 & 2.520 & \\
\hline
\end{tabular}

${ }^{\star} p \leq .05 ;{ }^{* \star} p \leq .01,{ }^{* *} p \leq .001$, n.s. $=$ not significant; ${ }^{a}$ Dispersion parameter $\alpha$. Significance indicates that a negative binomial model is preferred to a poisson model; ${ }^{b}$ Pseudo $\mathrm{R}^{2}$; $^{\mathrm{c}}$ Variance inflation factor.

Notes: $N=821$. To account for heteroscedasticity, we estimated all models using robust standard errors.

experiences occur while performing activities supported by gamified services and through which motivational processes they may foster continued service usage. This gap represents the starting point for our research, which aimed at uncovering the association of game mechanics with gameful experiences and showing how these experiences may encourage continued service usage through autonomous and controlled motivation.

By adopting a factor analytical approach, we identify four gameful experience dimensions: skill development, social comparison, social connectedness, and expressive freedom. Based on these dimensions, we further reveal four clusters of objective game mechanics that can be designed and are capable of triggering these experiences. Finally, by employing SUR, we tested how gameful experience dimensions enhance continued service usage by driving autonomous and controlled motivation. Specifically, we reveal that skill development, social connectedness, and expressive freedom drive continued app usage by supporting autonomous motivation. Further, even if controlled motivation is known for reducing self-determined behavior [8, 39], it does not necessarily hinder the promotion of continued service usage as it may also represent a manifestation of "other-determined" behavior. Thus, we point out that social comparison drives service usage as users act on perceived pressure. 
Based on our empirical evidence, we highlight important implications for service managers and app designers. By linking game mechanics with gameful experiences, we provide app designers with guidelines on how specific game mechanics translate into gameful experiences. Looking at gameful experiences helps designers to understand how the mechanics are perceived and continued service usage accrues. Taking into account that some experiences may foster stronger continued service usage (e.g., skill development), while others work through different motivational paths (e.g., social comparison), service managers now have the opportunity to better target their service design initiatives. Our results prevent managers from misreading certain mechanics as being ineffective in light of a classical motivational perspective although it has an impact if motivations are considered that have thus far been neglected.

Our two studies have some limitations that merit fruitful avenues for further research. For instance, we focused on communities, education, fitness, nutrition, and organization as focal app categories. Future research could tap into other categories such as banking or even other app platforms such as desktop operating systems where different gameful experiences may occur or the ones identified in this research may show different effects. The need to explore additional categories is underscored by the significant effects of the categoryspecific control variables included in Study 2, which demonstrate that motivation varies across app categories. Additionally, the results of Study 1 reveal that specific game mechanics relate especially to one gameful experience. Importantly, it still remains to be tested whether implementing more than one game mechanic from a cluster affects the related gameful experience positively or even negatively. For future research, it would be promising to examine the interplay of different gameful experiences and to examine whether these interactions boost or hinder continued service usage. In the same vein, future research endeavors should also focus on identifying moderating factors that may leverage or mitigate the impact of gameful experiences on continued app usage such as service-related (e.g., user integration) and user-related characteristics (e.g., network size).

\section{References}

[1] Amabile, T.M., K.G. Hill, B.A. Hennessey, and E.M. Tighe, "The Work Preference Inventory: Assessing Intrinsic and Extrinsic Motivational Orientations", Journal of Personality and Social Psychology, 66(5), 1994, pp. 950-967. [2] Bellman, S., R.F. Potter, S. Treleaven-Hassard, J.A. Robinson, and D. Varan, "The Effectiveness of Branded
Mobile Phone Apps", Journal of Interactive Marketing, 25(4), 2011, pp. 191-200.

[3] Bui, A., D. Veit, and J. Webster, "Gamification - A Novel Phenomenon or a New Wrapping for Existing Concepts?", ICIS Proceedings, 2015, pp. 1-21.

[4] Burke, B. "Why Gamification Is Not a Game", CIO Journal, 2014.

[5] Cameron, A.C., and P.K. Trivedi, Regression Analysis of Count Data, Cambridge University Press, Cambridge UK, 2013.

[6] Chou, Y.-K., Actionable Gamification: Beyond Points, Badges, and Leaderboards, CreateSpace Independent Publishers, North Charleston, 2016.

[7] Deci, E.L., H. Eghrari, B.C. Patrick, and D.R. Leone, "Facilitating Internalization: The Self-Determination Theory Perspective", Journal of Personality, 62(1), 1994, pp. 119142.

[8] Deci, E.L., R. Koestner, and R.M. Ryan, “A Meta-Analytic Review of Experiments Examining the Effects of Extrinsic Rewards on Intrinsic Motivation", Psychological Bulletin, 125(6), 1999, pp. 627-668.

[9] Deci, E.L., and R.M. Ryan, "The General Causality Orientations Scale: Self-Determination in Personality", Journal of Research in Personality, 19(2), 1985, pp. 109-134. [10] Deci, E.L., and R.M. Ryan, 'The 'What' and 'Why' of Goal Pursuits: Human Needs and the Self-Determination of Behavior", Psychological Inquiry, 11(4), 2000, pp. 227-268. [11] Deterding, S., D. Dixon, R. Khaled, and L. Nacke, "From Game Design Elements to Gamefulness: Defining "Gamification", Proceedings of the 2011 Annual Conference Extended Abstracts on Human Factors in Computing Systems - CHI EA '11, 15(2), 2011, pp. 9-15.

[12] Gagné, M., and E.L. Deci, "Self-Determination Theory and Work Motivation", Journal of Organizational Behavior, 26(4), 2005, pp. 331-362.

[13] Gatautis, R., J. Banyte, Z. Piligrimiene, E. Vitkauskaite, and A. Tarute, "The Impact of Gamification on Consumer Brand Engagement", Transformations in Business and Economics, 15(1), 2016, pp. 173-191.

[14] Hamari, J., "Do Badges Increase User Activity? A Field Experiment on the Effects of Gamification", Computers in Human Behavior, 71, 2017, pp. 469-478.

[15] Hamari, J., and J. Koivisto, "Why Do People Use Gamification Services?", International Journal of Information Management. 35(4), 2015), pp. 419-431.

[16] Hamari, J., J. Koivisto, and H. Sarsa, "Does Gamification Work? A Literature Review of Empirical Studies on Gamification", 47th Hawaii International Conference on System Sciences, 2014, pp. 3025-3034.

[17] Hanus, M.D., and J. Fox, "Assessing the Effects of Gamification in the Classroom: A Longitudinal Study on intrinsic Motivation, Social Comparison, Satisfaction, Effort, and Academic Performance", Computers and Education, 80, 2015, pp. 152-161.

[18] Hofacker, C.F., K. de Ruyter, N.H. Lurie, P. Manchanda, and J. Donaldson, "Gamification and Mobile Marketing Effectiveness", Journal of Interactive Marketing, 34, 2016, pp. 25-36.

[19] Hohenberg, S, and C. Homburg, "Motivating Sales Reps for Innovation Selling in Different Cultures", Journal of Marketing, 80(2), 2016, pp. 101-120. 
[20] Hollenbeck, J.R., H.J. Klein, A.M. O'Leary, and P.M. Wright, "Investigation of the Construct Validity of a SelfReport Measure of Goal Commitment", Journal of Applied Psychology, 74(6), 1989, pp. 951-956.

[21] Huotari, K., and J. Hamari, "A Definition for Gamification: Anchoring Gamification in the Service Marketing Literature", Electronic Markets, 27(1), 2017, pp. 21-31.

[22] Lamprinou, D., and F. Paraskeva, "Gamification Design Framework Based on SDT for Student Motivation", Proceedings of the International Conference on Interactive Mobile Communication Technologies and Learning, 2015, pp. 406-410.

[23] Liu, C.Z., Y.A. Au, and H.S. Choi, "Effects of Freemium Strategy in the Mobile App Market: An Empirical Study of Google Play", Journal of Management Information Systems, 31(3), 2014, pp. 326-354.

[24] Lucassen, G., and S. Jansen, "Gamification in Consumer Marketing - Future or Fallacy?", Procedia - Social and Behavioral Sciences, 148, 2014, pp. 194-202.

[25] Matallaoui, A., J. Koivisto, J. Hamari, and R. Zarnekow, "How Effective Is 'Exergamification'? A Systematic Review on the Effectiveness of Gamification Features in Exergames", Proceedings of the 50th Hawaii International Conference on System Sciences, 2017, pp. 3316-3325.

[26] Mathwick, C., N. Malhotra, and E. Rigdon, "Experiential Value: Conceptualization, Measurement and Application in the Catalog and Internet Shopping Environment", Journal of Retailing, 77(1), 2001, pp. 39-56.

[27] Mekler, E.D., F. Brühlmann, A.N. Tuch, and K. Opwis, "Towards Understanding the Effects of Individual Gamification Elements on Intrinsic Motivation and Performance", Computers in Human Behavior, 71, 2017, pp. 525-534. [28] Nicholson, S., "A User-Centered Theoretical Framework for Meaningful Gamification", Games + Learning + Society 8.0, 2012, pp. 1-7.

[29] Nysveen, H., "Intentions to Use Mobile Services: Antecedents and Cross-Service Comparisons", Journal of the Academy of Marketing Science, 33(3), 2005, pp. 330-346.

[30] O'Connell, C., " $24 \%$ of Users Abandon an App After One Use", Localytics, 2017. http://info.localytics.com/blog/24-ofusers-abandon-an-app-after-one-use.

[31] Oh, Y.K., and J. Min, "The Mediating Role of Popularity Rank on the Relationship Between Advertising and In-App Purchase Sales in Mobile Application Market", Journal of Applied Business Research, 31(4), 2015, p. 1311.

[32] Olsson, M., J. Hogberg, E. Wastlund, and A. Gustafsson, "In-Store Gamification: Testing a Location-Based Treasure Hunt App in a Real Retailing Environment", 49th Hawaii International Conference on System Sciences, 2016, pp. 1634 1641.

[33] Preacher, K.J., and A.F. Hayes, "Asymptotic and Resampling Strategies for Assessing and Comparing Indirect Effects in Multiple Mediator Models", Behavior Research Methods, 40(3), 2008, pp. 879-891.

[34] Preacher, K.J., D.D. Rucker, and A.F. Hayes, "Addressing Moderated Mediation Hypotheses: Theory, Methods, and Prescriptions", Multivariate Behavioral Research, 42(1), 2007, pp. 185-227.
[35] Robson, K., K. Plangger, J.H. Kietzmann, I. McCarthy, and L. Pitt, "Is It All a Game? Understanding the Principles of Gamification”, Business Horizons, 58(4), 2015, pp. 411-420.

[36] Ryan, R.M., and J.P. Connell, "Perceived Locus of Causality and Internalization: Examining Reasons for Acting in Two Domains", Journal of Personality and Social Psychology, 57(5), 1989, pp. 749-761.

[37] Ryan, R.M., and E.L. Deci, "Self-Determination Theory and the Facilitation of Intrinsic Motivation", American Psychologist, 55(1), 2000, pp. 68-78.

[38] Ryan, R.M., and E.L. Deci, "Intrinsic and Extrinsic Motivations: Classic Definitions and New Directions", Contemporary Educational Psychology, 25(1), 2000, pp. 54-67.

[39] Ryan, R.M., and E.L. Deci, "Overview of SelfDetermination Theory: An Organismic Dialectical Perspective", in Handbook of Self-Determination Research, 2002, pp. 3-33.

[40] Sailer, M., J.U. Hense, S.K. Mayr, and H. Mandl, "How Gamification Motivates: An Experimental Study of the Effects of Specific Game Design Elements on Psychological Need Satisfaction", Computers in Human Behavior, 69, 2017, pp. 371-380.

[41] Seaborn, K., and D.I. Fels, "Gamification in Theory and Action: A Survey", International Journal of Human-Computer Studies, 74, 2015, pp. 14-31.

[42] Sigala, M., "The Application and Impact of Gamification Funware on Trip Planning and Experiences: The Case of TripAdvisor's Funware", Electronic Markets 25(3), 2015, pp. 189-209.

[43] Suh, A., C. Wagner, and L. Liu, "The Effects of Game Dynamics on User Engagement in Gamified Systems", 48th Hawaii International Conference on System Sciences, 2015, pp. 672-681.

[44] Tan, M., and K.F. Hew, "Incorporating Meaningful Gamification in a Blended Learning Research Methods Class: Examining Student Learning, Engagement, and Affective Outcomes", Australasian Journal of Educational Technology, 32(5), 2016, pp. 19-34.

[45] Thiebes, S., S. Lins, and D. Basten, "Gamifying Information Systems: A Synthesis of Gamification Mechanics and Dynamics", 22nd European Conference on Information Systems, 2014, pp. 1-17.

[46] Wallace, D.T., and L.J. Silver, Econometrics: An Introduction, Addison-Wesley, Boston MA, 1988.

[47] Weiser, P., D. Bucher, F. Cellina, and V. De Luca, "A Taxonomy of Motivational Affordances for Meaningful Gamified and Persuasive Technologies", Proceedings of EnviroInfo and ICT for Sustainability, Atlantis Press, 2015, pp. 1-10.

[48] Welch, C., "Nike Redesigned Its Popular Running App, and Users are Very Angry", Vox Media, Inc., 2016. https://www.theverge.com/2016/8/27/12670716/nikerunning-app-bad-redesign.

[49] Zhao, X., J.G. Lynch Jr., and Q. Chen, "Reconsidering Baron and Kenny: Myths and Truths about Mediation Analysis", Journal of Consumer Research, 37(2), 2010, pp. 197-206. 